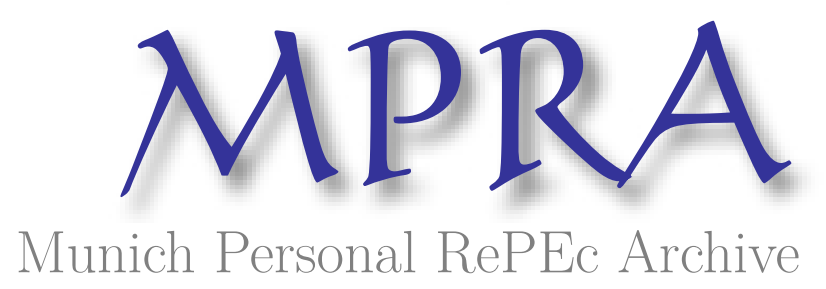

\title{
The value of a new idea: knowledge transmission, workers' mobility and market structure
}

Marini, Marco A.

Faculty of Economics, University of Urbino "Carlo Bo"

10 July 2005

Online at https://mpra.ub.uni-muenchen.de/1687/

MPRA Paper No. 1687, posted 07 Feb 2007 UTC 


\title{
The Value of a New Idea: Knowledge Transmission, Workers' Mobility and Market Structure*
}

\author{
Marco A. Marini ${ }^{\dagger}$ \\ Istituto di Scienze Economiche, \\ Facoltà di Economia, \\ Università degli Studi di Urbino "Carlo Bo"
}

July 2005

\begin{abstract}
We model the process of knowledge transmission among firms via workers' mobility as a multi-stage game. In our setup an idea to be realized needs that the agent informed about the idea recruits another agent from a pool of uninformed people. This constraint generates a recursive effect of knowledge transmission via players' mobility across firms which affects simultaneously the players' payoffs and the number of active players engaged in market competition. We provide sufficient conditions for the game to possess a unique symmetric subgame perfect equilibrium in which all incumbent players deter the exit of their collaborators. The equilibrium outcome is shown to depend upon the success of the idea over time, expressed by the behaviour of the market demand and on players' time preferences. A few other intuitions are provided on the interplay between technology, market structure and the market value of an innovative idea.
\end{abstract}

JEL Class. No.: CY, L2.

Keywords: Innovation, Workers' Mobility, Knowledge Transmission, Subgame Perfect Nash Equilibrium, Recursive Games.

\footnotetext{
${ }^{*}$ I really thank both the editors and the anonymous referees for their useful comments and suggestions which greatly helped to improve the paper.

${ }^{\dagger}$ Address for correspondence: Istituto di Scienze Economiche, Facoltà di Economia, Università degli Studi di Urbino "Carlo Bo", Via Saffi, 42, 60129, Urbino, Italy. Tel.+39-0722-305557. Fax: +39-0722-305550. E-mail: marinim@econ.uniurb.it.
} 


\section{Introduction}

The idea of considering a firm as an opportunity through which a group of different individuals can actively learn how to organize the production of a given commodity is certainly not new. Sometimes working together is just a technical necessity but more often it is also a crucial prerequisite to effectively develop the knowledge and the coordination necessary to obtain a more than ordinary result in production. The learning process usually requires a certain amount of time, e.g., if the firm starts producing at time 1, after a certain period, at time 2, each worker has learned how to organize the production. As a consequence, at time 2 the firm can generate a surplus, equal to the difference between the money value of the firm's production and the market prices of the factors. However, under complete information, the market for labour should reflect the value of such a surplus. Indeed, if a worker was to depart from the firm, he could use his knowledge to set up a rival firm in the market.

This is particularly the case in modern high-tech industries, where innovative ideas can hardly be protected at the development stage, and where therefore companies' scientists, engineers and CEOs can at times find convenient to move to a rival firm or set independent ventures. ${ }^{1}$ In fact, although formally companies are not completely vulnerable to the disclosure of their trade-secrets or their intellectual property rights, in reality Trade Secret Acts (like the Uniform TSA in U.S.), corporate policies on trade secrets as well as postemployment restrictive covenants, such as non disclosure and nonsolicitation agreements, are often violated. ${ }^{2}$ Moreover, when a key-employee sets up a new venture based on her organizational and market experience, companies do not really have grounds for a good lawsuit. It can be difficult to achieve evidence from which a court can infer that either customer lists, pricing and marketing plans or simply the company organizational style have been stolen. ${ }^{3}$

The idea that a worker can abandon the firm to setup a new venture dates back at least a few centuries. In a well known passage of the Wealth of Nations (1776), Adam Smith describes the causes of prosperity of new American colonies as a continuous process of transformation of initially subordinate workers into a group of independent producers: " The colonists carry out a knowledge of agriculture and of other useful arts...."; "Every colonist gets more land

\footnotetext{
${ }^{1}$ The most well known cases of this occurrence are reported for the high-tech district of Silicon Valley, with its extremely high rate of turnover and spontaneous spin-offs of highly skilled personnel (Carnoy et al. 1997, Saxenian 1994, Hyde 2000, Gilson 2000).

${ }^{2}$ See, for instance, for a discussion about the problematic enforceability of trade secrets law, Cheung (1982) and Fisk (2001).

${ }^{3}$ See Levin (1997) for a legal analysis of trade secrets and Besen and Raskind (1991) for the legal protection of property rights.
} 
than he can possibly cultivate... He is eager, therefore, to collect labourers from all quarters, and to reward them with the most liberal wages. But those liberal wages, joined to the plenty and cheapness of the land, soon make those labourers leave him, in order to become landlords themselves, and to reward, with equal liberality, other labourers, who soon leave them for the same reason ...." (book IV, part II, ch. VII).

The repeated and recursive process of formation of new production units appears as an important feature of a setup dealing with the issue of workers' effective outside option. Recently, there have mainly been two related issues which have attracted the attention of the economic literature. The first concerns the effects of the potential exit of the workers both on the level and distribution of earnings within the firm and on its internal organisation. ${ }^{4}$ These contributions recognize in different ways the possibility that wages, hierarchies and contractual relations between the firm and the workers can be shaped by the potential competitive threat of employees' departure from the firm with relevant information. However, none of these works model explicitly the potential recursive effect of information transmission and new firms formation via the repeated workers' departure from their company. Moreover, the role of market demand for a given product is not the main focus of these works.

A second important recent stream of literature mainly look instead at the issue of internal competition within innovative firms and the threat of information leakage at the developing stage of an innovation, when there are no effective intellectual property rights protecting inventors. ${ }^{5}$

Again, the dynamic effect of increasing competition is usually not the main focus of these papers, with the exception of Anton and Yao (1994) and Baccara and Razin (2004). Both these papers consider the threat of competition as a deterrence of information leakage and idea stealing. The first paper considers the problem of information leakage for an independent inventor sharing his project with a manufacturer. The inventor can protect his innovation and gain some rents by credibly threatening to reveal the idea to another competitor. However, the fact that the idea can also be stolen from the new competitor is not considered in the paper. In Baccara and Razin (2004) the sequence of information spillover among agents is directly modelled through a sequential bargaining process between informed and uninformed agents. Even so, this paper does not deal explicitly with the interaction between market demand for the product, matching technology and the length of the time horizon.

\footnotetext{
${ }^{4}$ See, among the others, Nitzan and Pakes (1982), MacLeod and Malcomson (1988), Mailath and Postlewaite (1990), Stole and Zwiebel (1996, 1997), Wolinsky (2000), Rajan and Zingales (2001) and Zabojnik (2002).

${ }^{5}$ See, Arrow (1962), Nitzan and Pakes (1982), Feinstein and Stein (1988), Anton and Yao (1994), Cooper (2001) Perotti (2004) and Baccara and Razin (2004)).
} 
Our paper proposes a very simple multi-stage game of knowledge transmission among agents across firms, via workers' mobility. Our setup assumes that initially only one agent possesses a new idea. However, to realize it commercially she needs to recruit at least another agent in the pool of existing agents, currently uninformed about the idea. This simple constraint is meant to capture the fact that usually for an inventor or a person with an innovative project it is extremely difficult to accomplish her project without the collaboration of people with different skills. ${ }^{6}$ Even if there are no substantial setup costs to start the business, for the inventor the need to share the idea with another person does not come for free: once involved in the project and before the actual production takes place, previously uninformed workers becomes informed and potentially ready to start a new venture to develop commercially the idea, again in collaboration with another (uninformed) agent. This spillover effect - in absence of well established intellectual property rights on new ideas - generates a recursive effect of knowledge transmission, affecting simultaneously the players' payoffs and the number of active players engaged in market competition. The fact that the learning process occurs both without cost and before the production process arises, is a crucial assumption of the model. If knowledge transmission would occur after the actual production of the innovative good, the inventor could pay her collaborator just his reservation wage, letting him go and then start again training (without cost) another uninformed worker. Given our assumptions, we can focus instead on the possibility that informed individuals either deter the exit of their collaborators by paying an "exit proof" wage, or favour their exit, thus voluntarily expanding the number of players involved and, hence, the market structure for the innovative product. If exit-deterrence takes place, we assume that the game ends and payoffs are assigned to both informed and uninformed players. This specific feature of the game is not relevant for its results. Even allowing the game to continue in all subsequent periods after deterrence has occurred, the game outcome would not change. The relevant trade off between exit deterrence and exit accommodation would remain, with the only difference that deterrence would continue for all remaining periods of the game.

We provide sufficient conditions for the game to possess a unique symmetric subgame perfect equilibrium in which incumbent players deter the exit of their collaborators. The equilibrium outcome is shown to mainly depend upon the success of the idea over time (i.e. its commercial acceptability), as expressed by the behaviour of the market demand, and on players' time preferences. A few other intuitions are provided on the interplay between

\footnotetext{
${ }^{6} \mathrm{It}$ is widely recognized that the commercial development of a new idea is usually a process which relies crucially on the interaction between many different individuals [see Callon (1989), Dodgson (1993) and Perotti (2003)].
} 
technology, market structure and the value of an innovative idea. The paper is organized as follows. The next section presents the game. Section 3 is devoted to illustrate the main results of the paper. Section 4 applies the results to some simple examples. Finally, section 5 concludes the paper.

\section{The Game}

The purpose of this section is to introduce a very simple model of transmission of an innovative idea between agents within firms. We assume that initially (period 1) only one agent (the innovator) possesses an idea on how to produce a new good. However, for the actual production to take place, she has to recruit an uninformed player, spend one period explaining him the project, offer him a wage and, if the player accepts, sell the commodity at the end of the period. The wage the innovator has to offer cannot simply be equal to the prevailing reservation wage. In fact, at period 2 the newly informed player is potentially able to leave the firm, recruiting another uninformed player and sell the commodity for his profit. However, the new producer is subject to the same exit threat from his worker, and similarly for all other subsequent leaving workers, until the market capacity, assumed given, cannot accommodate anymore competitors.

To translate the above problem in the most elementary fashion, let us introduce a multistage game $(t=1, \ldots T)$ with observed actions and with a set of players $N=\{1,2, . ., i, \ldots\}$ corresponding to the set of natural numbers. ${ }^{7}$ We denote by $I^{t} \subset N$ the subset of players fully informed about the new idea at time $t$; at time 1 only one of them is in $I^{1}$, i.e. disposes of a given knowledge (e.g. an innovative idea) on how to produce a given output $y$. We introduce simple assumptions on technology, market demand and knowledge transmission within each production unit.

Assumption 1 (Leontief production technology) For every $t=1,2, \ldots T, y^{t}=\min \left\{I^{t}, N \backslash I^{t}\right\}$ and no setup costs.

Assumption 2 (Inverse demand function) $P\left(Y^{t}\right): \Re_{+} \rightarrow \Re_{+}$twice continuously differentiable, with $Y^{t}=\sum_{i \in I^{t}} y_{i}^{t}, P(0)>0, P^{\prime}\left(Y^{t}\right)<0$ for all $P\left(Y^{t}\right)>0$ and $P\left(Y^{t}\right)$ log-concave for $P\left(Y^{t}\right)>0$.

\footnotetext{
${ }^{7}$ This allows to rule out any increase of wages as due to shortage of workforce.
} 
Assumption 3 (Knowledge transmission) At each time $t$, every player $j \in N \backslash I^{t}$ recruited by a player $i \in I^{t}$ acquires the full knowledge on how to produce $y^{t}$ before the actual production takes place.

Assumption 1 implies that any period of the game each informed player has to engage an uninformed player to produce the commodity. This constraint causes the transmission of knowledge within each production unit. The Leontief technology is the simplest and most extreme example of complementarity between an innovator (or an informed player) and an (unskilled) uninformed agents required to produce and commercialize an innovative product. Since the inclusion of setup costs - in absence of credit constraints - would not change the results of the model, we simply assume zero setup costs. Assumption 2 stipulates a standard downward sloping demand function starting from a point on the price axis and touching the quantity axis for a finite value of $Y^{t}$. We adopt here a partial equilibrium approach, excluding the possible (positive) feedback of the new entrants on the market demand for the new product. The implicit assumption is that either all active players do not consume the innovative good or their consumption does not have any impact on $P\left(Y^{t}\right)$. Log-concavity of $P\left(Y^{t}\right)$ is a crucial assumption for the characterization of a SNE of the game. ${ }^{8}$ Its economic meaning is that the expansion of the market (due to the entry of new firms) reduces the commercial value of the idea more when there are many (with a large $Y^{t}$ ) rather than few competitors (with a small $Y^{t}$ ). We postpone to the following sections a detailed discussion of the effect of the shape of market demand on the equilibrium of the game. Assumption 3 concerns the transmission of knowledge and, coupled with assumption 1 implies that if at time $(t-1)$ the wage offers does not satisfy the recruited agents and they leave their firms, at time $t$ the number of competing firms becomes $k^{t}=2^{(t-1)}$, each producing one unit of output (so also $Y^{t}=2^{(t-1)}$ ) and involving two players, one informed and one becoming informed at the end of the period. ${ }^{9}$ By assumptions 1-3 it also follows that informed players will surely stop recruiting workers for $P\left(Y^{t}\right)=0$, when proceeding further would make all players' payoffs lower than their reservation utility.

We can now describe the structure of the game. Every period of the game $t=1, \ldots T$ includes two stages, the first in which all informed agent play and the second in which is the turn of the uninformed ones. An action $a_{i}^{t}$ for an informed player $i \in I^{t}$ at period $t$ can be defined as a wage offer $w_{i}^{t} \in W \subset \Re_{+}$to a recruited player $j \in N \backslash I^{t}$ which, if accepted, is

\footnotetext{
${ }^{8}$ When smooth, $P(Y)$ is log-concave if and only if $P^{\prime \prime} P-\left(P^{\prime}\right)^{2} \leq 0$. It can be seen that this is a weaker assumption than concavity of $P\left(Y^{t}\right)$.

${ }^{9}$ The game can easily be extended (without qualitative changes) to the case of $m$ initial informed players. In this case, the number of firms composed of two players would be, at each stage $t, m^{(t-1)}$.
} 
assumed to directly imply the production of one unit of $y^{t}$ according to the given technology. An action $a_{j}^{t}$ for an uninformed player $j \in N \backslash I^{t}$ at stage $t$ (once recruited by an informed player) is a decision whether to accept the offered wage and jointly produce the good or reject it and leave as a newly informed player. Formally, $a_{j}^{t} \in\{y e s, n o\}$ for every $j \in N \backslash I^{t}$. Thus, the game is a sequence of periods in which all informed players simultaneously offer wages to recruited workers and, if the latter accept, production takes place and the game ends. If they reject the offer, the game proceeds from $t$ to $(t+1)$ and the number of informed players (and of potentially competing firms) duplicate (from $2^{(t-1)}$ to $2^{t}$ ).

Formally, a history of the game $H^{t}=\left(a^{1}, a^{2}, \ldots, a^{t-1}\right)$ is a sequence of action profiles $a^{h}=\left(a_{1}^{h}, a_{2}^{h}, \ldots, a_{n}^{h}\right)$ for $h=1$,..t before stage $t$. Each player's payoff can be represented as a function $u_{i}: H^{T+1} \rightarrow R$, where $H^{T+1}$ is the terminal history of the game. Specifically, in our game we assume linear utility functions and common discount factor $\delta \in(0,1)$ for all players. So, if the game terminates at time $t, u_{i}^{t}=\delta^{t} \pi_{i}^{t}=\delta^{t}\left[P\left(Y^{t}\right)-w_{i}^{t}\right]$ for all $i \in I^{t}$, and $u_{j}^{t}=\delta^{t} w_{i}^{t}$, for all recruited $j \in N \backslash I^{t}$. For all inactive players we assume $u_{i}^{t}=0 .{ }^{10}$

The concept of equilibrium used to solve the game is a standard symmetric subgame perfect equilibria (SNE) in pure strategies.

\section{Main Results}

It is easy to see that the model described above possesses a recursive nature. Consider, for instance, the potential payoff of the only informed player at $t=1$. Since inaction implies zero payoff, player $i \in I^{1}$ has an incentive to offer a wage $w^{1}$ to a player in $N \backslash I^{1}$ which, if accepted, implies the production of one unit of $y$, so $y^{1}=1$, with payoff

$$
u_{i}^{1}=\delta \pi^{1}=\delta\left[P\left(Y^{1}\right)-w^{1}\right]
$$

where, according to the Leontief technology, $Y^{1}=2^{1-1}=1$. However, if the informed player wants to prevent the exit of her worker before production occurs, she has to ensure him at least what he could gain at the end of the following period, that is:

$$
w^{1}=\delta^{2} \pi^{2}=\delta^{2}\left[P\left(Y^{2}\right)-w^{2}\right] .
$$

where $Y^{2}=2^{(2-1)}=2$ and

$$
w^{2}=\delta^{3}\left[P\left(Y^{3}\right)-w^{3}\right],
$$

\footnotetext{
${ }^{10}$ By the symmetry between every informed and every uninformed player, respectively, we will drop the index from their payoffs: $\pi=\pi_{i}$ for every $i \in I^{t}$ and $w=w_{j}$ for every $j \in N \backslash I^{t}$.
} 
with $Y^{3}=2^{(3-1)}=4$, and so on, until time $T$ is reached. Therefore, it is obvious that an informed player $i \in I^{t}$ has an incentive to deter the exit of her worker only if $\delta^{t} \pi^{t} \geq \delta^{t+m} \pi^{t+m}$, for $m=1, \ldots(T-t)$, i.e. if:

$$
\delta^{t}\left[P\left(Y^{t}\right)-w^{t}\right] \geq \delta^{t+m}\left[P\left(Y^{t+m}\right)-w^{t+m}\right]
$$

or

$$
\delta^{t} P\left(Y^{t}\right)-\delta^{t+m} P\left(Y^{t+m}\right) \geq \delta^{t} w^{t}-\delta^{t+m} w^{t+m} .
$$

The economic meaning of expression (5) is that an informed player will find convenient to pay an "exit-proof" wage to her worker only if the expected loss in revenue (due to the fact that $P^{\prime}\left(Y^{t}\right)<0$ and $Y^{t}$ grows over periods) is bigger than the expected saving in term of wage, given that time and increasing competition reduce both. However, the right-hand side of expression (5) includes terms which, in turn, potentially depend on all future histories of the game. In particular, it is possible to represent the payoffs of both informed and uninformed players in the event that all present and future informed players want to prevent the exit of their employees and the latter decide to accept the offer. These are:

$$
u_{i}^{1}=\sum_{t=1}^{T} \prod_{h=1}^{t} \delta^{h} P\left(2^{t-1}\right)(-1)^{(t-1)}
$$

for $i \in I^{1}$

$$
u_{j}^{1}=w^{1}=\delta^{2} \pi^{2}=\sum_{t=2}^{T} \prod_{h=2}^{t} \delta^{h} P\left(2^{t-1}\right)(-1)^{(t-1)},
$$

for the enrolled worker $j \in N \backslash I^{1}$.

Similarly, if the game ends at a generic period $\widetilde{t}$, expression (6) becomes:

$$
u_{i}^{\widetilde{t}}=\delta^{\widetilde{t}} \pi^{\widetilde{t}}=\sum_{t=\widetilde{t}}^{T} \prod_{h=\widetilde{t}}^{t} \delta^{h}\left(P\left(2^{t-1}\right)\right)(-1)^{(t-\widetilde{t})}
$$

and each active worker's payoff at time $\widetilde{t}$ is just equal to:

$$
u_{j}^{\widetilde{t}}=w^{\widetilde{t}}=\delta^{\widetilde{t}+1} \pi^{\widetilde{t}+1}=\sum_{t=\widetilde{t}+1}^{T} \prod_{h=\widetilde{t}+1}^{t} \delta^{h}\left(P\left(2^{t-1}\right)\right)(-1)^{(t-\widetilde{t}+1)} .
$$

Let us describe now the full conditions required for the game to terminate at time $t$. The game ends at time $t$ only if the following condition holds:

$$
\delta^{t} \pi^{t} \geq \delta^{t+m} \pi^{t+m}
$$


for all $m=1, \ldots, T-t$, where,

$$
w^{t} \geq \delta^{t+m} \pi^{t+m}
$$

for all $m=1, \ldots,(T-t)$. Conditions (10) and (11) guarantee that at an arbitrary period $t$ for both an informed player and her worker, there is no incentive to change action and continue the game. ${ }^{11}$

The next lemma shows some of the properties of the recursive payoff (8), which, as said before, assumes as specific history that at all periods every informed player offers an exitdeterrence wage to the worker, and this accepts it.

The lemma ensures that at each time $t$, for both informed and uninformed players, the payoffs (8) and (9) are positive. This ensures that at every stage for each $i \in I^{t}$ is more convenient to hire an uninformed player and paying him an exit-proof wage rather than staying inactive (when $u_{i}=0$ ), and for every $j \in N \backslash I^{t}$ is more convenient to accept such a wage than being inactive.

Lemma 1 When an exit-deterrence wage is offered and accepted at every $t=1,2 \ldots T$, time $t$ players' payoffs (8) and (9) are non negative.

Proof. As a start suppose that both $t$ and $T$ are even. Hence,

$$
\begin{aligned}
u_{i}^{\widetilde{t}}= & \sum_{t=\widetilde{t}}^{T} \prod_{h=\widetilde{t}}^{t} \delta^{h}\left(P\left(2^{(t-1)}\right)(-1)^{(t-\widetilde{t})}=\right. \\
= & \delta^{\widetilde{t}}\left[P\left(2^{\widetilde{t}-1}\right)-\delta^{\widetilde{t}+1} P\left(2^{\widetilde{t}}\right)\right]+\delta^{\widetilde{t}} \delta^{\widetilde{t}+1} \delta^{\widetilde{t}+2}\left[P\left(2^{\widetilde{t}+1}\right)-\delta^{\widetilde{t}+3} P\left(2^{\widetilde{t}+2}\right)\right]+ \\
& +\ldots .+\delta^{\widetilde{t}} \delta^{\widetilde{t}+1} \ldots \delta^{T-2}\left[P\left(2^{T-2}\right)-\delta^{T-1} P\left(2^{T-1}\right)\right] .
\end{aligned}
$$

By assumptions 1-2, $P\left(Y^{t}\right)$ is decreasing in $t$ and, as a consequence, expression (12) is positive. It easy to see that the same holds for $\widetilde{t}$ even and $T$ odd, $\widetilde{t}$ odd and $T$ even and for the case in which they are both odd. The same occurs for each recruited worker's payoffs, given that $u_{j}^{\widetilde{t}}=u_{i}^{\widetilde{t}+1}$ for all $j \in N \backslash I^{t}$.

We are now ready to provide sufficient conditions for the existence of a SNE of the game with complete exit deterrence. In doing this, the main purpose is to gain a better understanding of the processes at work in the model. In particular, the result below sheds some light on the reasons why at the equilibrium the endogenous market structure is a monopoly or any other market form.

\footnotetext{
${ }^{11}$ Note that each player, once informed, can move from a period to the next by just paying her worker a wage $w^{t}<\pi^{t+1}$
} 
Proposition 1 For $\delta \leq \frac{\left[P\left(Y^{2}\right)^{2}+P\left(Y^{1}\right) 4 P\left(Y^{2}\right)\right]^{\frac{1}{2}}-P\left(Y^{2}\right)}{2 P\left(Y^{2}\right)}$, the game ends at time $t=1$ and the only symmetric SNE of the game is the strategy profile in which at every stage $t=1, \ldots T$, informed players propose a deterrence wage as in (9) and every worker accepts it.

Proof. Since the demand intersects the quantity axis for a finite quantity, we denote as $T$ the final period of the game, such that $P\left(Y^{T}\right) \leq 0$. Reasoning backward, at stage $(T-1)$ every informed player willing to keep her trained worker inside the firm has to offer a wage $w^{T-1}=\delta^{T} P\left(Y^{T}\right)=0$, and play $\{a c c e p t\}$ will be a weakly dominant action for each worker. Therefore, every informed proposer will find optimal to offer this (reservation) wage obtaining $\delta^{T-1} \pi^{T-1}=\delta^{T-1}\left[P\left(Y^{T-1}\right)\right]$. In turn, at stage $(T-2)$, each informed player will have an incentive to prevent the exit of her workers only if:

$$
\delta^{T-2} \pi^{T-2} \geq \delta^{T-1} \pi^{T-1}
$$

that is

$$
\delta^{(T-2)}\left[P\left(Y^{T-2}\right)-w^{T-2}\right] \geq \delta^{(T-1)} P\left(Y^{T-1}\right),
$$

which can be written as

$$
\delta^{(T-2)}\left[P\left(Y^{T-2}\right)-\delta^{(T-1)} P\left(Y^{T-1}\right)\right] \geq \delta^{(T-1)} P\left(Y^{T-1}\right),
$$

i.e.,

$$
\delta^{(T-2)} P\left(Y^{T-2}\right) \geq \delta^{(T-1)} P\left(Y^{T-1}\right)\left(1+\delta^{(T-2)}\right)
$$

which can be simplified as

$$
\frac{P\left(Y^{T-2}\right)}{P\left(Y^{T-1}\right)} \geq \frac{\left(\delta^{T-1}+\delta^{2 T-3}\right)}{\delta^{(T-2)}}=\delta+\delta^{T-1} .
$$

The same procedure can be repeated at every period $t$. If all informed players will prevent the exit of their co-workers at all following stages, the condition for the game to be a SNE with deterrence at stage $t$ is:

$$
\delta^{t} \pi^{t} \geq \delta^{t+1} \pi^{t+1} \geq \ldots \geq \delta^{T-1} \pi^{T-1}
$$

with

$$
\begin{aligned}
w^{t}= & \delta^{t+1} \pi^{t+1}, \\
w^{t+1}= & \delta^{t+2} \pi^{t+2}, \\
& \cdots . \\
w^{T-1}= & \delta^{T} \pi^{T} .
\end{aligned}
$$


Let us consider just the first inequality in (16), $\delta^{t} \pi^{t} \geq \delta^{t+1} \pi^{t+1}$; using (8), (9) and (17), for $T$ and $t$ both even, we obtain

$$
\begin{aligned}
& \delta^{t} P\left(Y^{t}\right)-\delta^{t} \delta^{t+1} P\left(Y^{t+1}\right)+\delta^{t} \delta^{t+1} \delta^{t+2} P\left(Y^{t+2}\right)-. .-\delta^{t} \delta^{t+1} \delta^{t+2} . . \delta^{T-1} P\left(Y^{T-1}\right) \\
\geq & \delta^{t+1} P\left(Y^{t+1}\right)-\delta^{t+1} \delta^{t+2} P\left(Y^{t+2}\right)+\ldots . .+\delta^{t+1} \delta^{t+2} . . \delta^{T-1} P\left(Y^{T-1}\right)
\end{aligned}
$$

or

$$
\begin{aligned}
& \delta^{t} P\left(Y^{t}\right)-\left(1+\delta^{t}\right) \delta^{t+1} P\left(Y^{t+1}\right)+ \\
& +\left(1+\delta^{t}\right)\left[\delta^{t+1} \delta^{t+2} P\left(Y^{t+2}\right)-\delta^{t+1} \delta^{t+2} \delta^{t+3} P\left(Y^{t+3}\right)\right]+ \\
& +\left(1+\delta^{t}\right)\left[\delta^{t+1} \delta^{t+2} \delta^{t+3} \delta^{t+4} P\left(Y^{t+4}\right)-\delta^{t+1} \delta^{t+2} \delta^{t+3} \delta^{t+4} P\left(Y^{t+5}\right)\right]+\ldots+ \\
& +\left(1+\delta^{t}\right)\left[\delta^{t+1} \delta^{t+2} \delta^{t+3} \delta^{t+4} \cdot \delta^{T-2} P\left(Y^{T-2}\right)-\delta^{t+1} \delta^{t+2} \delta^{t+3} \cdots \delta^{T-1} P\left(Y^{T-1}\right)\right],
\end{aligned}
$$

where the terms in square brackets are all positive. Thus, the condition above will certainly be respected when the first term is positive, that is, for

$$
\delta^{t} P\left(Y^{t}\right)-\left(1+\delta^{t}\right) \delta^{t+1} P\left(Y^{t+1}\right) \geq 0
$$

which can be rewritten as

$$
\frac{P\left(Y^{t}\right)}{P\left(Y^{t+1}\right)} \geq \frac{\left(\delta^{t+1}+\delta^{2 t+1}\right)}{\delta^{t}}=\delta+\delta^{t+1} .
$$

By assumption, $P\left(Y^{t+1}\right)$ is both decreasing and log-concave in $Y^{t}$. Moreover, given that the number of firms $k^{t}=2^{(t-1)}$, it follows that:

$$
\left[k^{t+2}-k^{t+1}\right]>\left[k^{t+1}-k^{t}\right]
$$

for every $t=1, . . T$, and this implies that

$$
Y^{t+2}-Y^{t+1}>Y^{t+1}-Y^{t},
$$

again for every $t=1, . . T$.

Condition (19) and the log-concavity of $P\left(Y^{t}\right)$ together imply that

$$
\frac{P\left(Y^{T-2}\right)}{P\left(Y^{T-1}\right)} \geq \frac{P\left(Y^{T-3}\right)}{P\left(Y^{T-2}\right)} \geq \ldots \geq \frac{P\left(Y^{t}\right)}{P\left(Y^{t+1}\right)} \geq . . \geq \frac{P\left(Y^{1}\right)}{P\left(Y^{2}\right)}
$$


Hence, if:

$$
\frac{P\left(Y^{1}\right)}{P\left(Y^{2}\right)} \geq \delta+\delta^{2}
$$

the equilibrium condition (18) will a fortiori hold for every $t=1, \ldots T$. Condition (20) is solved for

$$
\delta \leq \frac{\left[P\left(Y^{2}\right)^{2}+P\left(Y^{1}\right) 4 P\left(Y^{2}\right)\right]^{\frac{1}{2}}-P\left(Y^{2}\right)}{2 P\left(Y^{2}\right)} .
$$

Thus, for such a (positive) discount rate, at every time $t=1, \ldots T$ all informed players prefer to deter the exit of their workers.

Proposition 1 provides sufficient conditions for the game to end at the first period and for the initial informed player (the innovator) to receive part of the rent for the idea. Note that in general the concavity of the inverse demand function makes the strategy of exit deterrence relatively less interesting at the first period of the game, when second period market price is very close to that of the first period: the loss in gross revenue by accommodating new entrants is small and lower than the gain in wage reduction (which reflects all following stage revenues). Therefore, with a concave demand, which reflects an initial slow decline in the value of the invention, the game is more likely to terminate at latter stages. The economic intuition is that when players are patient $(\delta \simeq 1)$ and the price for the good does not fall much initially for the entry of new competitors, at the beginning of the product life we should expect inventors easily allowing information leakages, and play deterrence later. The role of log-concavity in the model is thus which to make the first period demand variations a threshold for game deterrence: if exit deterrence is profitable at time 1 , it will be throughout the game. Moreover, the presence of a sufficiently low discount factor, reflecting the impatience of players, makes the first "inventor" sufficiently sensitive to the initial loss of profit, thus making profitable to play exit-deterrence at the first period.

\section{Examples and Discussion}

To illustrate the main results of the paper, and in particular the role of both the shape of the demand and the discount factor to give rise to different SNE, we assume a simple market inverse demand for the product equal to $P\left(Y^{t}\right)=\left(a-Y^{t}\right)^{\beta}$, where $a=2^{(T-1)}$ represents market capacity. Let $T=5$, so the market accommodates only $k^{T}=2^{4}=16$ firms, i.e., for $t=5, P\left(Y^{T}\right)=0$. Note that the demand is strictly concave (and then log-concave) for $0<\beta<1$, log-concave for $\beta=1$ (the usual linear case) and convex for $\beta>1$.

Let us assume first, for simplicity, that $\beta=\delta=1$, so the basic assumptions of the model hold. Reasoning backward, at time $t=(T-1)=4$, a number $k^{4}=8$ of competing 
firms have entered the market, each one composed of one informed and one uninformed player. Since $w^{T-1}=\pi^{T}=0$, at time 4 every informed player will obtain a payoff equal to $P\left(Y^{T-1}\right)-w^{T-1}=\left(a-Y^{T-1}\right)-0=(16-8)=8$. Hence, at $t=(T-2)=3$, with only 4 active firms, informed players will pay a deterrence wage only if

$$
P\left(Y^{3}\right)-w^{3} \geq P\left(Y^{4}\right)-w^{4},
$$

where $w^{3}=\pi^{4}=8$. Condition (22) does not hold, since

$$
P\left(Y^{3}\right)-w^{3}=(16-4)-8=4<P\left(Y^{4}\right)-w^{4}=8 .
$$

So, at time 3 , all informed players will let the market expand by paying a $w^{3}=0$ to all recruited workers. At time $t=2$, with 2 firms in the market, we have, instead:

$$
P\left(Y^{2}\right)-w^{2}=(16-2)-8=6<8 .
$$

where, as deterrence wage, we have applied $w^{2}=\pi^{4}$. Also in this case, there is no interest to deter the exit of the workers. Finally, at time $t=1$,

$$
P\left(Y^{1}\right)-w^{1}=(16-1)-8=7<8,
$$

and the only subgame perfect equilibrium of the game is to pay a non deterrence wage $w=0$ to uninformed players at every stage, ending the game at stage $t=4$. Note that by log-concavity of $P\left(Y^{t}\right)$, the condition on inverse demand over time holds:

$$
\frac{P\left(Y^{3}\right)}{P\left(Y^{4}\right)} \geq \frac{P\left(Y^{2}\right)}{P\left(Y^{3}\right)} \geq \frac{P\left(Y^{1}\right)}{P\left(Y^{2}\right)}
$$

since

$$
\frac{12}{8} \geq \frac{14}{12} \geq \frac{15}{14}
$$

However, this is not enough: by proposition 1 (with $\delta=1$ ), for the game to end at the first stage (full deterrence) we would need

$$
\frac{P\left(Y^{1}\right)}{P\left(Y^{2}\right)} \geq 2
$$

which does not hold for the demand of the example.

It is clear from this example that demand log-concavity plays a role in making the strategy of exit deterrence relatively less interesting when the product is initially sold in the market. As said above, with a log-concave (or concave) demand, the game is likely to terminate at last stages. 
Let us now briefly see what happens if $\delta \neq 1$ and the discount factor respects the constraint of proposition 1. In our example, with $\beta=1$,

$$
\delta \leq \frac{\left[P\left(Y^{2}\right)^{2}+P\left(Y^{1}\right) 4 P\left(Y^{2}\right)\right]^{\frac{1}{2}}-P\left(Y^{2}\right)}{2 P\left(Y^{2}\right)}=\frac{\sqrt{14^{2}+4(14) 15}-14}{2(14)}=.645 .
$$

Taking, for instance, $\delta=.5$, we have:

$$
\frac{P\left(Y^{1}\right)}{P\left(Y^{2}\right)}=\frac{15}{14} \geq .5+(.5)^{2}=.75,
$$

and by proposition 1 , the game will end at time 1 . Thus, with a sufficiently low discount factor, all informed players are sufficiently impatient so that playing an exit-deterrence strategy at each period become a weakly dominant strategy, even in presence of a log-concave demand.

On the other hand, a convex demand is more sensitive to quantity shifts at the initial rather than the at the last stages of the game. However, in our model last stages are characterized by a larger number of entrants, so the final result can be ambiguous. To illustrate this point let the demand of our example be convex, by assuming $\beta=2$ and, again $\delta=1$. By looking backward at the informed players' payoffs, we have:

$$
\begin{aligned}
& \pi^{4}=P\left(Y^{4}\right)-w^{4}=P\left(Y^{4}\right)-\pi^{5}=\left(2^{4}-8\right)^{2}-0=64 \\
& \pi^{3}=P\left(Y^{3}\right)-w^{3}=P\left(Y^{3}\right)-\pi^{4}=\left(2^{4}-4\right)^{2}-64=80 \\
& \pi^{2}=P\left(Y^{2}\right)-w^{2}=P\left(Y^{2}\right)-\pi^{3}=\left(2^{4}-2\right)^{2}-80=126 \\
& \pi^{1}=P\left(Y^{1}\right)-w^{1}=P\left(Y^{1}\right)-\pi^{2}=\left(2^{4}-1\right)^{2}-126=99 .
\end{aligned}
$$

At stage 2 and 3 workers' exit is conveniently deterred, but not at stage 1 . So the game will end at stage 2 . Therefore, in general convexity makes things difficult to predict in our setup, except for the isoelastic case presented at the end of the section. On the one hand, demand convexity makes price shifts hit dramatically at the initial rather than at the final stages of commercialization of an invention. So we should expect more deterrence at the beginning of production. However, since by assumption the number of firms grow exponentially over periods, deterrence may become convenient also when the market is mature.

To conclude, let us illustrate a peculiar example which makes clear-cut the role of market demand on the problem at stake. This is the case of isoelastic demand, with $P(Y)=A Y^{-\frac{1}{\epsilon}}$ where $\epsilon$ represents the (absolute value of) elasticity of demand. In this case it is easy to see that, for $\delta=1$, at every stage:

$$
\frac{P\left(Y^{t}\right)}{P\left(Y^{t+1}\right)}=\frac{A\left(2^{t-1}\right)^{-\frac{1}{\epsilon}}}{A\left(2^{t}\right)^{-\frac{1}{\epsilon}}} \geq 2 \Leftrightarrow \epsilon \leq 1 .
$$


The way to interpret the condition is clear: when the demand is rigid, the market price falls considerably with the rise of output (as due to the entry of new firms) making crucial to deter the expansion of the market. For an elastic demand, the opposite holds: price is insensitive and thus expanding the market is less costly than keeping all workers inside the firm.

\section{Concluding Remarks}

The paper has presented a simple dynamic setting to analyze the issue of knowledge transmission within a firm first, between an inventor and her workers, and across firms after, when workers' mobility is not prevented with a compensation higher than a given reservation wage. The model shows that, in absence of property rights, the value of an idea each period depends on all future events, in which the market expands and new players become able to sell the product. In this scenario, the crucial factors to shape the final market structure for the product are the demand sensitivity over time, the time preferences of players and, of course, the technology of production. In particular, this paper has constrained each informed player to match at least another player to organize appropriately the production of the good. However, different technologies could generate different results and the outcome would thus depend on the intensity of demand effect as compared to the efficiency effect (wage saving effect and returns of scale of technology), both due to the expansion of the market. A more detailed and deep analysis of this complex trade off will be matter for future research.

\section{References}

[1] Anton, J., and D. Yao, (1994), "Expropriation and Inventions", American Economic Review, 190-209.

[2] Arrow K. (1962), Economic Welfare and the Allocation of Resources for Inventions, in: The Rate and Direction of Inventive Activity, Nelson (eds.), Princeton University Press, New York.

[3] Baccara M. and R. Razin (2002), "From Thought to Practice: Appropriation and Endogenous Market Structure with Imperfect Intellectual Property Rights", mimeo, New York University.

[4] Beser S.M. and L.J.Raskind (1991), "An Introduction to the Law and Economics of Intellectual Property", Journal of Economic Perspectives, 51. 
[5] Callon, M., (1989), La science et ses réseaux, La Découverte, Paris.

[6] Carnoy, M., Castells, Benner C., (1997)"Labour Market and Employment Practises in the Age of Flexibility: a Case Study in Silicon Valley", International Labour Review, 136 (1).

[7] Cheung, S. (1992), "Property Rights in Trade Secrets", Economic Inquiry.

[8] Feinstein, J.S. and J., Stein (1988), "Employee opportunism and redundancy in firms", Journal of Economic Behaviour and Organization, 10, 4.

[9] Cooper, D., P. (2001), Innovation and Reciprocal Externalities: Information Transmission via Job Mobility", Journal of Economic Behaviour, 45, 403-25.

[10] Dodgson, M., (1993), Learning, trust and technological collaboration, Human Relations, 46,7794 .

[11] Fisk C. (2001), Working Knowledge: The Employment Relationship and Corporate Ownership of Intellectual Property, 1800-1930, mimeo, Loyola University.

[12] Gilson R.J. (2000), "The Legal Infrastructure of High Technology Industrial Silicon Valley, Route 128, and Covenantes Not to Compete", NYU Law Review, 74.

[13] Hyde A. (2000), "Working in Silicon Valley: Economic and Legal Analysis of a HighVelocity Labor Market", mimeo.

[14] Levin, R. C., Klevorick, A. K., Nelson, R.R. Winter, S. G. (1987), "Appropriating the Returns from Industrial R \& D", Brooking Papers on Economic Activity, 783-820.

[15] MacLeod, W. B., and J. M. Malcomson, (1988) "Reputation and Hierarchy in Dynamic Models of Employment", Journal of Political Economy, 96 , 832-54.

[16] Mailath, G. and A., Postlewaite (1990), "Bargaining over the firm value", Review of Economics Studies, 57, pp.367-90.

[17] Pakes, A. and S. Nitzan (1983), "Optimum Contracts for Research Personnel, Research Employment, and the Establishment of "Rival" Enterprises," Journal of Labor Economics, Vol. 1 (4) pp. 345-65.

[18] Perotti R. (2003), "Entrepreneurs and Ideas", mimeo, University of Amsterdam. 
[19] Saxenian, A. (1994), Regional Advantage: Culture and Competition in Silicon Valley and Route 128. Cambridge (Mass.), Harvard University Press.

[20] Rajan R.G. and L.Zingales (2001), "The Firm as a Dedicated Hierarchy: A Theory of the Origin and Growth of Firms", Quarterly Journal of Economics, 116.

[21] Smith, A. (1776), An Inquiry into the Nature and Causes of the Wealth of Nations. London, George Bell \& Sons.

[22] Stole, Lars A. and Zwiebel, Jeffrey (1996), "Organizational design and technology choice under intra-firm bargaining", American Economic Review, 86, 1, pp. 195-221.

[23] Stole, Lars A. and Zwiebel, Jeffrey (1997), "Intra-firm bargaining under non-binding contracts", Review of Economic Studies, 3, pp. 375-410.

[24] Wolinsky A. (2000), A Theory of The Firm With Non Binding Employment Contracts", Econometrica, 69.

[25] Zabojnik J. (2002), "A Theory of Trade Secrets in Firms", International Economic Review, 43. 